\title{
AVALIAÇÃO DO DESENVOLVIMENTO DE MUDAS DE JENIPAPO (Genipa americana L.) E DE URUCUM (Bixa orellana L.) INOCULADAS COM FUNGOS MICORRIZICOS ARBUSCULARES DESTINADA À COMUNIDADE INDÍGENA GAVIÃO KYIKATÊJÊ
}

\author{
Domisley Sompré Sena ${ }^{1}$; Andréa Hentz de Mello \\ ${ }^{1}$ Discente do curso de Agronomia, Faculdade de Ciências Agrárias de Marabá (FCAM), Universidade Federal do Pará \\ (UFPA), Marabá, Pará. Bolsista PROINT. E-mail: domisleyss@ hotmail.com. \\ ${ }^{2}$ Prof. $^{\mathrm{a}}$, D.Sc., FCAM, UFPA. Email: andreahentz@ufpa.com.
}

RESUMO: Espécies nativas amazônica são de grande importância na manutenção da biodiversidade deste bioma, bem como na vida e cultura dos povos amazônidas. As espécies Jenipapo (Genipa americana L.) e Urucum (Bixa orellana L.) são muito utilizados na vida cotidiana dos índios Gavião Kyikatêjê. No entanto, tem-se dificuldade em encontrar as espécies dentro da comunidade, tendo que buscá-las em reservas distantes. Portanto, este trabalho tem como objetivo a produção de mudas das referidas espécies inoculadas com Fungos Micorrízicos Arbusculares (FMAs.) visando maximizar o desenvolvimento das plantas destinadas a atender a insuficiência desses recursos na comunidade indígena Kyikatêjê, e de identificar e avaliar a associação micorrízicas no solo da área da comunidade com as plantas das espécies estudadas, além de coletar da área indígena, reproduzi-las em banco de inóculo e estimular a inoculação. Este trabalho constará da identificação de FMAs nativos, multiplicação e produção de um banco de inoculo e produção das mudas inoculadas. A identificação dos FMA's nativos constará de caracterização pelo método direto e indireto. Na identificação direta, será realizada a extração de esporos por peneiramento úmido e centrifugação em sacarose. O procedimento de extração de esporos de FMA's do solo será feito a partir de uma amostra de solo, composta de 10 sub-amostras coletadas na profundidade de $0-20$ $\mathrm{cm}$. Desta amostra composta de solo, será retirada uma amostra de $50 \mathrm{~g}$, a partir da qual será realizada a contagem dos esporos. Os esporos serão preparados em laminas e identificados segundo suas características morfológicas. Outra parte do solo será utilizada para identificação indireta dos FMA's, onde irá ser instalado em casa de vegetação, um cultivo armadilha com Brachiaria brizantha com o objetivo de recuperação das espécies de fungos, que não estavam esporulados no momento da coleta. As unidades experimentais serão vasos de $1000 \mathrm{~g}$, nos quais será feita a semeadura com Brachiaria brizantha em alta densidade visando forçar o desenvolvimento do sistema radicular. $\mathrm{Na}$ avaliação da colonização micorrízica, as raízes serão clarificadas e coradas. A porcentagem do comprimento de raízes colonizada será avaliada pelo método da intersecção em placa quadriculada. As mudas das essências florestais serão produzidas em casa de vegetação em vasos plásticos de capacidade de $1000 \mathrm{~g}$ de solo, com substrato fértil e inoculadas com os fungos micorrízicos. Para a determinação dos teores de nutrientes a parte aérea das mudas será seca a $65^{\circ} \mathrm{C}$ até atingir massa constante. A partir daí será moído e digerido com extrator nitroperclócrico (2:1) para extração de $\mathrm{P}, \mathrm{K}, \mathrm{Ca}$ e $\mathrm{Mg}$ e extrator sulfúrico para extração de $\mathrm{N}$. Os teores de $\mathrm{P}$ serão determinados por colorimetria, $\mathrm{K}$ por fotometria de chama e $\mathrm{Ca}$ e $\mathrm{Mg}$ por espectrofotometria de absorção atômica e o N pelo método de KJELDAHL modificado. Espera-se um bom desenvolvimento radicular das plantas inoculadas com os fungos micorrízicos arbusculares, bem como um bom crescimento nas áreas de plantio mostrando a eficiência dessa abordagem.

PALAVRAS-CHAVE: Solos, espécies nativas, biodiversidade. 